\title{
Relative Prices and Wages in China: Evidence from a Panel of Provincial Data
}

\author{
Jun Nagayasu \\ University of Tsukuba \\ Ying Liu \\ ShanDong University
}

\begin{abstract}
Using Chinese provincial data, we examine the relationship between relative prices and wages, which can be derived on the basis of the Balassa-Samuelson theorem. First, considering cross sectional dependency in our data, we implement recently developed panel unit root tests. We report strong evidence of non-divergence in the prices of provinces vis-a-vis those of the benchmark (Beijing) and weaker evidence in wages. In the latter case, the results seem sector-specific, suggesting that wages in some industries are not following the trend in Beijing. Secondly, using sectorlevel data, we find evidence that relative prices can be explained by relative wages.
\end{abstract}

- JEL classification: E300, F300

- Keywords: Purchasing power parity, the Balassa-Samuelson effect, panel unit root tests, convergence speed, Chinese provincial data, bootstrap methods

\section{Introduction}

This paper empirically analyzes the relationship between relative prices and wages in China. Our motivation in carrying out this research is connected to the deficiencies

\footnotetext{
*Corresponding address: Nagayasu, Graduate School of Systems and Information Engineering, University of Tsukuba, 1-1-1 Tennodai, Tsukuba, Ibaraki 305-8573 Japan, Email Nagayasu@sk.tsukuba.ac.jp. Ying Liu, School of Economics, ShanDong University, 27 Shanda Nanlu, Jinan, P.R. China 250100. 
in the Purchasing Power Parity (PPP) theory. For decades, PPP has been a very influential hypothesis in the area of international finance. This theorem asserts that the nominal exchange rate be determined by home and foreign prices, and can be expressed in logarithmic form as $s_{t}=p_{t}-p_{t}^{*}$ where $s_{t}$ is nominal exchange rates, and $p_{t}$ and $p_{t}^{*}$ are domestic and foreign prices. Thus, an increase in domestic prices will bring about exchange rate depreciation, other things being constant.

Due to its popularity and simplicity, efforts have been made in order to evaluate the hypothesis using different data sets and statistical methodologies. Along with the developments in time-series methods (e.g., integration and cointegration) over the last couple of decades, researchers have recently investigated the long-run PPP concept by testing whether the real exchange rate $\left(r_{t}=s_{t}-p_{t}+p_{t}^{*}\right)$ is stationary, i.e., $r_{t} \sim I(0)$. Unlike classical studies based on the OLS, the integration method has made long-run analysis possible because it allows for deviation of the nominal exchange rate from the long-run path.

While it may be controversial to draw a consensus from existing literature, previous studies have tended to provide evidence against PPP when using country-level data and conventional statistical methods. The traditional explanations for violation of PPP are, among many other factors, the existence of tariff and non-tariff barriers, taxes, transportation costs, as well as the heterogeneous composition and weight of commodities included in the basket to produce the aggregated price indices (e.g., Rogoff 1995). But when the nonlinearity of the real exchange rate is considered, there is more evidence of PPP. Taylor, Peel, and Sarno (2001) argue that the presence of transaction costs results in the nonlinear adjustment of the real exchange rate data. This nonlinear behavior is argued as consistent with the mean reverting movement of the real exchange rate. Furthermore, when PPP is analyzed in the panel data context (e.g., using panel unit root tests), some evidence is obtained of PPP (e.g., MacDonald 1996).

Another explanation for violation of PPP frequently used by researchers is the Balassa-Samuelson (BS) effect (Balassa 1964, Samuelson 1964). They argue that distortion in PPP arises from recognition of the tradable and non-tradable goods sectors in a country, and results from the differences in productivity between these two sectors. Accordingly, during the process of economic development, productivity tends to increase more quickly in the tradable goods sector than in the non-tradable sector. Given that the prices of tradable goods are determined in the international market (i.e., PPP), an increase in productivity in this sector leads to an increase in wages. Since this increase in wages spreads across the economy as a whole, there 
is a rise in prices in the non-tradable goods sector, even where productivity has not grown at the same pace. Higher prices of non-tradable goods transmit higher inflation into the domestic economy and lead the overall real exchange rate to appreciate.

In recognition of these classical explanations for violation of PPP, we shall analyze PPP using Chinese provincial data. Compared with the traditional approach of using country-level price data, our approach should reduce the likelihood of barriers across borders such as heterogeneous tariffs, and data compilation methods. Furthermore, use of regional data allows us to ignore the nominal exchange rate (i.e., $s_{t}=0$ ) since under monetary union provinces share a single currency. ${ }^{1}$ This line of research has been carried out using the data of industrialized countries. For example, Engle and Rogers (1996) and Parsley and Wei (1996) raise evidence for price convergence among US cities. Similar results are obtained for European countries (Chen 2004) and for Japan (Esaka 2003, Nagayasu and Inakura 2006). Furthermore, Rogers (2001), Esaka (2003) and Goldberg and Verboven (2005) find that convergence is especially evident for traded goods.

Such research has not been widely conducted for less developed countries. One exception is Guillaumont Jenneney and Hua (2002). They study the BS effect using productivity data in the Chinese context. However, unlike previous studies based on the two-goods/two-regions (the tradable and nontradable) model that concerns productivity within a single country or unified monetary area, they also consider productivity differentials with other trading countries outside the monetary union, like Japan and the US, that should be significant in China. Furthermore, they propose a three-goods model creating another category of goods for industrial raw materials and foodstuffs, called semitradables. Such items are often protected by governments either to satisfy the domestic market demand or to guarantee the revenues of producers. Therefore, their definition of an exchange rate is rather different from the conventional model and is closer to that of the effective exchange rate.

While endorsing the direction of their research, we retain the traditional framework. This is largely due to a different research focus and limited data availability. Thus, as will be elaborated later, unlike Guillaumont Jenneney and Hua, this paper employs a two-province model, which makes our results more comparable to previous research. Furthermore, we utilize sector-specific wage data rather than productivity (per

${ }^{1}$ Thus, the real exchange rate is equivalent to the relative price in this paper. 
capita GDP) as used by Guillaumont Jenneney and Hua, which enables us to conduct research at the more micro level. In this regard, this study may not be regarded as research directly analyzing the Balassa-Samuelson effect. Finally, we employ more advanced (appropriate) statistical methods considering crosssectional dependence in the data when evaluating the PPP. O'Connell (1998) argued that cross-sectional dependence severely affects the finite sample properties of standard panel tests, and shows that results are very sensitive to the treatment of cross-sectional correlation. In this connection, this paper implements the recently developed panel unit root test (Moon and Perron 2004). In short, this study should complement previous studies on China.

\section{The Relative Price-Wage Relationship}

The relationship between relative prices and wages can be derived from the Balassa-Samuelson (BS) theorem (Balassa 1964, Samuelson 1964). This theorem asserts that a high growth economy experiences appreciation of the real exchange rate, which arises from the existence of tradable and non-tradable goods. Therefore, the BS effect offers one explanation of why PPP does not hold. While this theorem has been extensively analyzed, the statistical model used differs from researcher to researcher partly due to data availability. Therefore, below, we shall explain briefly this theory which leads us to analyze the relationship between price and wage ratios.

The BS hinges on several economic assumptions. First, we assume that all provinces produce output $(Y)$ using labor $(L)$ as an input. For the sake of simplicity, let us focus on two provinces in China.

$$
\begin{aligned}
& Y_{T}=f\left(L_{T}\right) \\
& Y_{N}=f\left(L_{N}\right) \\
& Y_{T}^{*}=f\left(L_{N}^{*}\right) \\
& Y_{N}^{*}=f\left(L_{N}^{*}\right)
\end{aligned}
$$

where $d Y / d L>0$ and $d^{2} Y / d L^{2}>0$ are assumed, and the asterisk indicates the variable for the benchmark (foreign) province. Subscripts, $T$ and $N$, are used to distinguish between tradable and non-tradable goods. The tradable goods may include agricultural and manufacturing commodities, while non-tradable goods are 
services (Balassa 1964).

Secondly, the firms are assumed to operate in the perfect competitive market with an assumption of constant returns to scale, and perfect international and internal capital mobility. Furthermore, if the firms are profit-maximizers, their behavior for example in the tradable goods sector at home can be expressed as

$$
\max _{T}=P_{T} f\left(L_{T}\right)-w_{T} L_{T}-F_{T}
$$

where wages are $w$ and fixed costs are $F$. A similar expression is assumed to hold in other sectors and provinces. The first order condition of this problem is

$$
\frac{d \pi_{T}}{d L_{T}}=P_{T} \frac{d Y_{T}}{d L_{T}}-w_{T}=0
$$

Thirdly, labor is perfectly mobile within each province (but not across provinces) $)^{2}$ and the labor market is perfectly competitive. Therefore, wages $(w)$, the product of the price and the marginal physical product of labor $(d Y / d L)$, tend to equalize within the province. In other words,

$$
\begin{aligned}
& P_{T} f^{\prime}\left(L_{T}\right)=w=P_{N} f^{\prime}\left(L_{N}\right) \\
& P_{T}^{*} f^{\prime}\left(L_{T}^{*}\right)=w^{*}=P_{N}^{*} f^{\prime}\left(L_{N}^{*}\right)
\end{aligned}
$$

Fourth, the PPP holds only in the tradable goods sector across provinces.

$$
P_{T}=P_{T}^{*}
$$

Balassa (1964) suggests that a higher productivity differential exists in the tradable goods sector across provinces than in the non-tradable goods sector and also that productivity in the non-tradable goods sector is more or less identical across provinces $\left(f^{\prime}\left(L_{N}\right)=f^{\prime}\left(L_{N}^{*}\right)\right)$. If these observations and equation (2) hold, it follows that higher productivity in home tradable goods $\left(f^{\prime}\left(L_{T}\right)>f^{\prime}\left(L_{T}^{*}\right)\right)$ should indicate higher home prices $\left(P_{N}>P_{N}^{*}\right)$ for nontradable goods.

Assuming that the overall price $(P)$ is the sum of the weighted prices of tradable

\footnotetext{
${ }^{2}$ Lack of labor mobility across provinces may be an appropriate assumption in China because of the residency permits. A residency permit allows one to live in a particular area (except for the special administrative regions of Hong Kong and Macau). Without a residency permit, one has considerably less access to education and government services. Furthermore, until 2003, the police were authorized to enforce the return of the unregistered to their permanent residence.
} 
and nontradable sectors,

$$
\begin{gathered}
P=P_{T}^{\alpha} P_{N}^{1-\alpha} \\
P^{*}=\left(P_{T}^{*}\right)^{\alpha}\left(P_{N}^{*}\right)^{1-\alpha}
\end{gathered}
$$

where $0<\alpha<1$. We can obtain the following real exchange rate equation using equations (2) and (3),

$$
R=\frac{P^{*}}{P}=\frac{\left(P_{T}^{*}\right)^{\alpha}\left(P_{N}^{*}\right)^{1-\alpha}}{P_{T}^{\alpha} P_{N}^{1-\alpha}}=\left(\frac{P_{T}^{*}}{P_{T}}\right)\left(\frac{P_{N}^{*}}{P_{N}}\right)^{1-\alpha}
$$

If PPP holds in the tradable goods sectors, this equation can be simplified as.

$$
R=\left(\frac{P_{N}^{*}}{P_{N}}\right)^{1-\alpha}=\left(\frac{w_{N}^{*} / f^{\prime}\left(L_{N}^{*}\right)}{w_{N} / f^{\prime}\left(L_{N}\right)}\right)^{1-\alpha}
$$

Since productivity for nontradable goods is assumed to be the same across provinces $\left(f^{\prime}\left(L_{N}^{*}\right)=f^{\prime}\left(L_{N}\right)\right)^{3}$, equation (5) can be further simplified as:

$$
R=\left(\frac{w_{N}^{*}}{w_{N}}\right)^{1-\alpha}
$$

Since $1-\alpha>0$, this equation asserts a negative relationship between the real exchange rate and the home wage for nontradable goods. Therefore, even if PPP holds for tradable goods, the existence of nontradable goods $(0 \neq \alpha)$ and the heterogenous level of wages in the nontradable goods sector across provinces (i.e., $\left.w_{N} \neq w_{N}^{*}\right)$ become reasons for the violation of PPP. In short, this equation suggests that when the home province experiences higher productivity growth in the tradable goods sector than that in the benchmark province and when the productivity differentials are reflected in increased wages in the home non-tradable goods sector, equation (6) implies real exchange rate appreciation for the home province. This is called the BS effect.

Finally, based on equalization of the wages in different sectors within the same

\footnotetext{
${ }^{3}$ The equalization of productivity in nontradable goods sectors across provinces may not be an appropriate assumption. Indeed, MacDonald and Ricci (2005) and Altissimo, Benigno and Palenzuela (2005) argue that different growth in productivity in the nontradable goods (e.g., services and distribution sectors) is a significant explanatory factor in explaining the real exchagne rates. However, because the productivity data (e.g., GDP per capita) consistent with our industry classification (Tables 1-3) are not available, this assumption is used to derive the simpler relationship between the real exchange rate and relative wage like equation (7). In this connection, when a strong relationship cannot be found in our data, lack of consideration of productivity in the nontradable goods sector may be attributable to the result.
} 
province (equation (1)), equation (6) becomes

$$
R=\left(\frac{w_{N}^{*}}{w_{N}}\right)^{1-\alpha}=\left(\frac{w_{T}^{*}}{w_{T}}\right)^{1-\alpha}
$$

One notable feature of equations (6) and (7) is that a positive relationship is expected between the real exchange rate (or the relative price) and wage ratio, regardless of the economic sector. Obviously, equation (7) is very simple and hinges on a number of economic assumptions that may not hold in China where state-owned enterprises still play a significant role in the economy. Nonetheless, equation (7) is suitable for empirical analysis there where few statistical data are disseminated and available for academic research.

Much related research has been carried out in the international and long-run contexts (e.g., Canzoneri, Chinn and Johnston 1997, Cumby, and Diba 1999, and Faria and Leon-Ledesma 2003), and some (and overall less) research has been conducted on a regional basis (e.g., Honohan and Lane 2003, Chen 2003 , and Nagayasu and Inakura 2006). Our data are region-specific, and the real exchange rate is defined as relative prices. Therefore, it is not clear whether the relative pricewage relationship is a long-term phenomenon in our study. Against this background, we shall first of all examine the order of integration of our data in a panel context. If they are nonstationary, the relative price-wage relationship may have a long-run implication. But, if both are stationary, this effect can be viewed as a temporary occurrence.

\section{Data}

Our analysis is based on the annual data of the 29 "provinces" in China from 1995 to $2005^{4}$. This group covers the 22 provinces (Hebei, Shanxi, Liaoning, Jilin, Heilongjiang, Jiangsu, Zhejiang, Anhui, Fujian, Jiangxi, Shandong, Henan, Hubei, Hunan, Guangdong, Hainan, Sichuan, Guizhou, Yunnan, Shaanxi, Gansu, and Qinghai), the three autonomous municipalities under the direct control of the central government (Beijing, Tianjin, and Shanghai), and the four autonomous regions (Inner Mongolia, Guangxi, Ningxia, and Xinjiang). Tibet is not considered here because of lack of data availability, and Chongqing, created in 1997, is treated in the data set as part of Sichuan. Our data set consists of prices and wages, all

${ }^{4}$ Our sample period is longer than that of Guillaumont Jenneney and Hua (2002) whose analysis is based on 8 years of observations. 
obtained from the China Statistical Yearbook. More specifically, prices are measured by the Consumer Price Index (CPI) and wages are the average wages of staff and workers by sector and region (province).

As for sectoral classification, we follow that of the National Bureau of Statistics of China which distinguishes 15 industries (1.agriculture, forestry, animal husbandry, fishing; 2. mining; 3. manufacturing; 4. production/distribution of electricity, gas, water; 5. construction; 6. management of water, conservancy; 7. transport, storage, post; 8. wholesale, retail trade; 9 . financial intermediation; 10. real estate; 11 services to households, other services; 12 . health, social securities and welfare; 13. education; 14. scientific research, technical services; 15. public management, social organization). Such sector-level analysis has an advantage over one based on the three sector classification (primary, secondary, and tertiary); for example, Balassa (1964) regards the primary (agriculture) and secondary (manufacturing) sectors as tradable goods and tertiary (services) as non-tradable goods. But dividing an economy into tradables and nontradables is always somewhat imprecise because many goods referred to as tradable, contain some nontradable components, e.g., transport services, and so on (Wincenciak 2005). ${ }^{5}$ For this reason and equation (7), we shall not attempt to classify these industries into tradeable and nontradable sectors but will utilize data from all industries.

In addition to the CPI, this paper uses the Retail Price Index (RPI) which is available from 1985 to 2005 for 27 provinces and is obtained from the World Bank database. Out of the 29 provinces mentioned before, Hubai and Hunan are not included here due to non-availability of data.

All the variables considered are transferred into logarithms, i.e., log relative prices $\left(\ln \left(P^{*} / P_{i}\right)\right)$ and $\log$ relative average wages $\left(\ln \left(W^{*} / W_{i}\right)\right)$. Since Beijing is the capital of China, we regard it as a benchmark (foreign) province to test the real exchange rate.

The data on average CPI (for the country as a whole) and average sector-level

${ }^{5}$ De Gregorio, Giovannini and Wolf (1994) assume that a given sector is tradable whenever its export share of production exceeds ten percent. But this of course rules out sectors which exhibit strong import competition, which should also be treated as tradable, because we may expect the law of one price to hold. Orlowski (2001) considers goods with a standard deviation lower than 20 percent as tradable. Wincenciak (2005) treats as tradable sectors where the export share of its production or import penetration ratio is higher than ten percent. He also treats all sections of manufacturing and coal mining as tradable goods and the remaining parts of the economy as nontradable. This classification is a very rough approximation, and significant components in agriculture which were viewed as tradable may contain nontradable components. 
wages (for each province) are shown in Figures 1 and 2. These graphs give us a sense that there is a significant discrepancy in the price and wage levels among provinces. Such regional differences appear to be key to understanding the dynamics of the Chinese economy. Since the BS effect has been frequently observed in dynamic economies, this effect likely exists in China. Finally, Figure 3 presents a positive relationship between the average CPI and overall wage levels and shows that this relationship does not seem very strong since some observations are concentrated in the area of a high CPI and low wage.

\section{The Stationarity of Relative Prices and Wages}

This section examines the time series properties of our data (both relative prices and wages) since our statistical model is based mainly on these two factors and therefore requires them to be integrated of the same order so that the model will be statistically balanced. In order to improve the deficiencies of cross section (individual) unit root tests in a near-unit root case, most previous research has employed panel unit root tests. Parsley and Wei (1996) use the panel unit root developed by Levin and Lin [LL] (1993), while Cecchetti, Mark, and Sonora (2002) use the tests developed by LL, and Im, Pesaran, and Shin [IPS] (2003).

Figure 1. Average CPI (1995-2005) by 29 Provinces

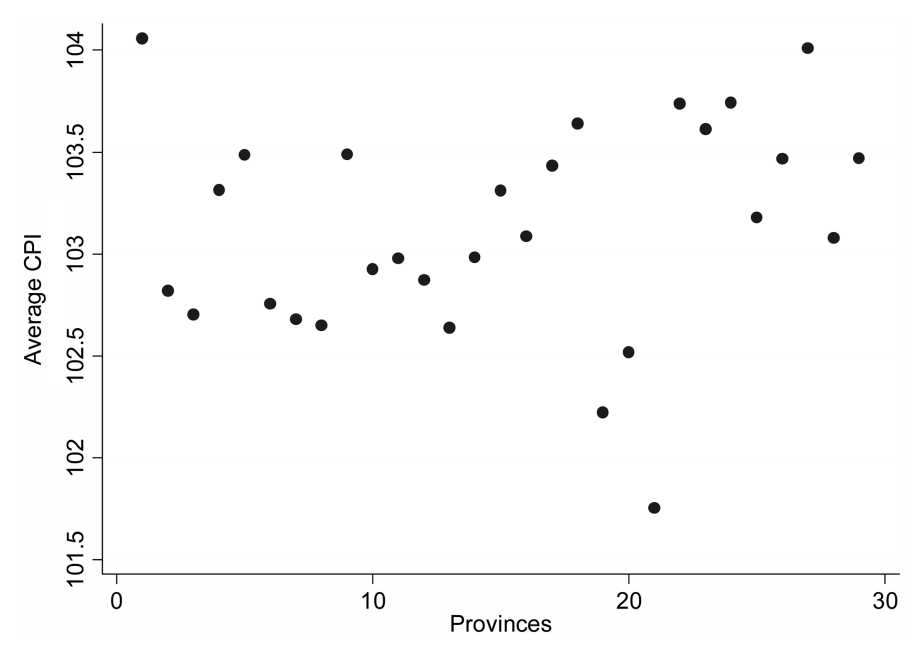

Note: The order of provinces is Beijing, Tianjin, Hebei, Shanxi, Inner Mongolia, Liaoning, Jilin, Heilongjiang, Shanghai, Jiangsu, Zhejiang, Anhui, Fujian, Jiangxi, Shandong, Henan, Hubei, Hunan, Guangdong, Guangxi, Hainan, Sichuan, Guizhou, Yunnan, Shaanxi, Gansu, Qinghai, Ningxia, and Xinjiang. 
Figure 2. Average Sector-Level Wages (1995-2005) for 29 Provinces
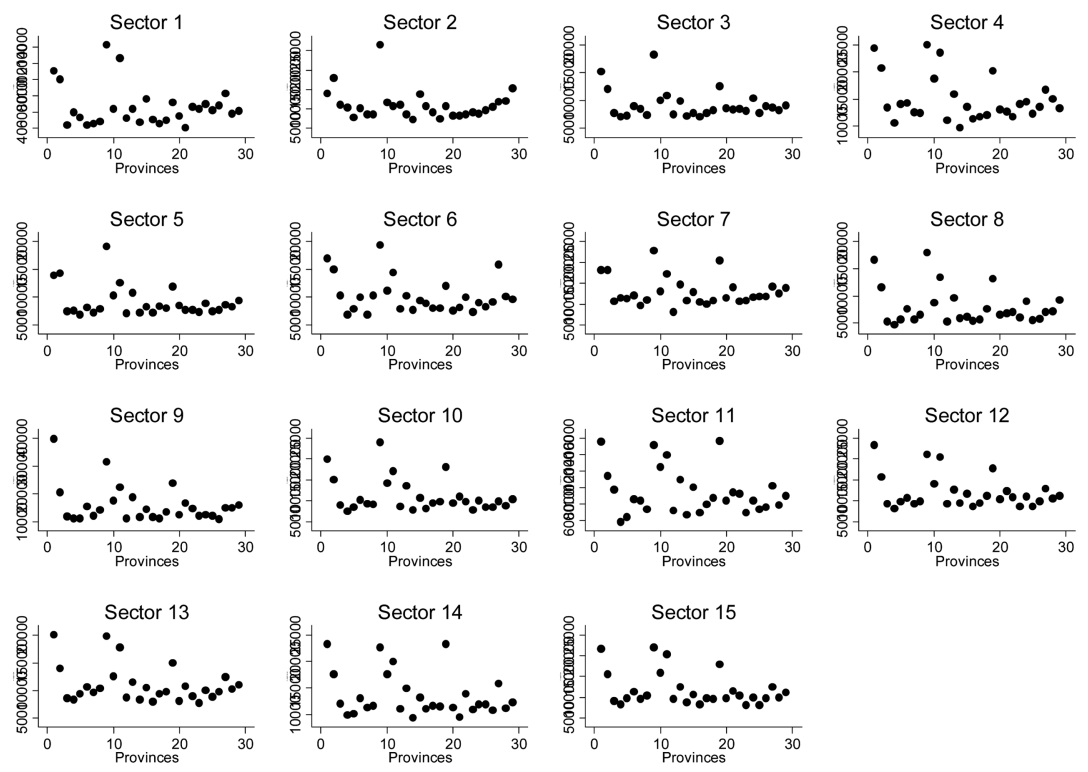

Note: The order of sectors is consistent with that in Table 1.

Figure 3. Average CPI and Overall Wages (1995-2005) for 29 Provinces

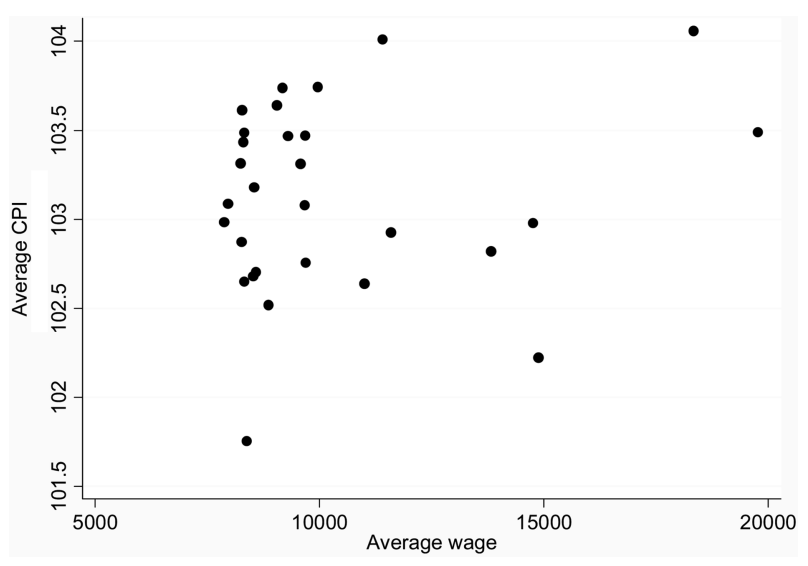

Esaka (2003) uses the IPS and Fisher (1932) tests, Nagayasu and Inakura (2006) use the LLC, IPS, and Fisher. (The Levin-Lin-Chu [LLC] (2002) test is a modified version of the LL test.) Finally, Guillaumont Jeanneney and Hua (2002) use the IPS. We also implement the panel unit root tests since our sample period is limited.

While the total observations may increase by pooling time-series data, these 
panel unit root tests assume no cross-sectional dependence in the data. This assumption, however, does not seem to hold in most economic and financial data, including ours, because of the existence of exogenous stocks which likely exist within the same country. Thus, this paper employs the panel unit root test developed by Moon and Perron (2004) in order to address this deficiency in the standard panel tests. The results from this test will be compared with the LLC results adjusted for cross sectional dependence since their null hypothesis differs. ${ }^{6}$

\section{A. The LLC test}

The LL (1993) and LLC (2002) are seminal papers in the area of panel unit root tests that take account of nonspherical disturbances. For panel data consisting of cross sections $(i=1, \ldots, N)$ and time $(t=1, \ldots, T)$, the test can be conducted estimating the following equation by OLS.

$$
\Delta y_{i, t}=\alpha_{i}+\rho y_{i, t-1}+\sum_{j=1}^{k_{i}-1} \beta_{i, j} \Delta y_{i, t-j}+u_{i, t}
$$

This is similar to the ADF test for univariate data, and like the ADF test, autocorrelation, for example, can be adjusted by taking an appropriate lag order $k_{i}$. There are two distinctive features. First, this test analyzes the alternative hypothesis with the same value for $\rho_{i}$ for all cross sections: the null hypothesis of the unit root is $\rho=1$ against the alternative of stationarity $\rho<1$. In particular, this alternative hypothesis differs from many other tests such as the IPS which assume different values for $\rho_{i}$ among cross sections under the alternative. Maddala and $\mathrm{Wu}$ (1999) argue that this is very restrictive and view this as the major limitation of this test. However, we regard this test as a convenient measure for drawing a general conclusion. If the alternative hypothesis is $\rho_{i}<1$ for some $i$, the conclusion from the test becomes cross-section specific. The way this test is constructed has a further advantage when cross-sectional cointegration relationships exist. Banerjee, Marcellio and Osbat (2005) argue that when there are such relationships in the data, the panel tests too often reject the null. However, the LL test is found to suffer least from this effect among panel unit root tests.

${ }^{6}$ Some researchers (e.g., Banerjee, Marcellino, and Osbat 2005) warn against use of the panel unit root test. 
Secondly, like the IPS test, it assumes cross section independence. A number of researchers, notably O'Connell (1998) point to the fact that economic and financial data are often cross sectionally correlated. He shows that ignorance of crosssectional dependence where it actually exists leads to erroneous conclusions-evidence of a stationary process. Using the real exchange rate (country vis-a-vis country), he demonstrates that the null of the unit root cannot be rejected. Since our data are likely more contemporaneously correlated because they are from the same country, this may be worthwhile addressing. In this connection, we use the adjusted LLC that removes the cross sectional averages from equation (8).

\section{B. The MP test}

Moon and Perron [MP] (2004) have proposed an approach to deal with cross sectional dependency by estimating cross sectional components and using the principal component method. Therefore, in addition to the LLC, we employ this method as well. The MP test can be summarized using the following equations.

$$
\begin{gathered}
q_{i, t}=\alpha_{i}+q_{i, t}^{0} \\
q_{i, t}^{0}=\rho_{i} q_{i, t-1}^{0}+u_{i, t} \\
u_{i, t}=\lambda_{i}^{\prime} f_{t}+e_{i, t}
\end{gathered}
$$

where $i=1, \ldots, N$ and $t=1, \ldots, T$, and $q_{i, t}^{0}$ is the difference between fixed effects $\left(\alpha_{i}\right)$ and $q_{i, t}$ which is the relative price or wage in this study. Like the IPS test, this test examines the null hypothesis of the unit root (i.e., $\rho_{i}=1 \forall_{i}$ ) against the alternative of stationarity (i.e., $\rho_{1}<1$ for some $i$ ). The unique feature of this test can be summarized in equation (11) where $\lambda_{i} f_{t}$ is common components of $u_{i, t}$ and $e_{i, t}$ idiosyncratic factors. Furthermore, $\lambda_{i}^{\prime} f_{t}$ can be decomposed into common factors $\left(f_{t}\right)$ and factor loadings $\left(\lambda_{i}\right)$. Thus, $u_{i, t}$ contains only idiosyncratic factors if $\lambda_{i}^{\prime} f_{t}=0$, and $u_{i, t}$ contains only common factors if $e_{i, t}=0$. MP proposes to decompose into two such components using the standard principle component method.

\section{The results}

Prior to analysis of the relationship between the price and wage ratios, we shall check the order of integration of these data. This is equivalent to testing whether or not prices (wages) are diverging from the benchmark and should be interesting 
since the Chinese economy has been growing very fast over recent years with an annual GDP growth of about 10 percent, but the gap is often said to be widening between the eastern (rich) and middle/western (poor) areas. In 2005, economic activities in the east accounted for 63 percent of national GDP, the middle 26 percent, and the west 11 percent. The GDP per capita of the east is almost double that of the middle region and 2.6 times of the west. Recognizing this problem, the Chinese government began to implement the West China Development Drive in 1999---a comprehensive scheme to reduce this economic gap by promoting infrastructure, improving the living standards of farmers, assisting ethnic minorities, and improving the educational system in the west. However, while the economic gap between the middle and west narrowed, the gulf between the eastern and middle areas increased. Therefore, in 2004, the government proposed the Program of the Rise of the Middle Area which facilitates economic developments in the middle zone.

Table 1 summarizes the results from the panel unit root tests for relative prices and wages. We implement the MP and adjusted LLC tests. The adjusted LLC test is the one that removes cross sectional averages. Generally, it shows that our real exchange rates (i.e., relative prices) are stationary (non-divergent), which is consistent with previous studies using European, Japanese and US regional data. But, our results for the wage ratio are less conclusive. Indeed, while wages in most sectors are following the trend of Beijing, in some sectors they are not. Using the 10 percent significance level, there are five sectors, out of 15 , where the null cannot be rejected by the adjusted LLC although the MP rejects its null. The different null hypotheses between these tests seem attributable to this outcome, and thus the empirical results from these two tests are not contradicted. Furthermore, according to the adjusted LLC test, the overall wage data show no evidence of stationarity.

The relatively weak evidence of stationary wage ratios in five sectors implies that wage behaviors in Beijing differ from those in other provinces. While further research is required, the nonstationary results may, at least in part, be attributable to the labor shortage and lack of market accessibility. Unskilled, cheap labor is often said to be in high demand in the manufacturing and construction sectors. One might expect that improvements in access to information technology (e.g., the spread of mobile phone use) would help solve this imbalance in the labor market (Inagaki 2002). But this did not materialize and might have resulted in asymmetric changes in wages across provinces. Furthermore, Beijing has advantages over 
Table 1. Results of the Panel Unit Root Tests

\begin{tabular}{|c|c|c|c|c|}
\hline & LLC & MP & $\rho$ & Half-life \\
\hline \multicolumn{5}{|l|}{ Prices } \\
\hline CPI & $-7.157(0.000)$ & $-8.788(0.000)$ & 0.373 & 0.703 \\
\hline RPI & $-8.354(0.000)$ & $-12.056(0.000)$ & 0.213 & 0.473 \\
\hline \multicolumn{5}{|l|}{ Wages } \\
\hline Overall wages & $0.075(0.530)$ & $-4.008(0.000)$ & 0.295 & -- \\
\hline $\begin{array}{l}\text { Agriculture, forestry, animal husbandry, } \\
\text { fishing }\end{array}$ & $-3.826(0.000)$ & $-5.226(0.000)$ & 0.540 & 1.125 \\
\hline Mining & $-3.800(0.000)$ & $-5.809(0.000)$ & 0.440 & 0.844 \\
\hline Manufacturing & $-0.566(0.286)$ & $-7.364(0.000)$ & 0.521 & -- \\
\hline $\begin{array}{l}\text { Production/distribution of electricity, } \\
\text { gas water }\end{array}$ & $-1.830(0.034)$ & $-4.361(0.000)$ & 0.633 & 1.516 \\
\hline Construction & $-0.882(0.189)$ & $-7.048(0.000)$ & 0.524 & -- \\
\hline Management of water, conservancy & $-1.251(0.106)$ & $-5.395(0.000)$ & 0.649 & -- \\
\hline Transport, storage, postage & $-5.173(0.000)$ & $-9.535(0.000)$ & 0.371 & 0.699 \\
\hline Wholesale, retail trade & $-4.611(0.000)$ & $-6.164(0.000)$ & 0.466 & 0.908 \\
\hline Financial intermediation & $-1.810(0.035)$ & $-6.235(0.000)$ & 0.658 & 1.656 \\
\hline Real estate & $-1.810(0.035)$ & $-9.312(0.000)$ & 0.433 & 0.828 \\
\hline Services to households, other services & $4.263(1.000)$ & $-5.840(0.000)$ & 0.719 & -- \\
\hline Health, social security and welfare & $-4.967(0.000)$ & $-5.873(0.000)$ & 0.450 & 0.868 \\
\hline Education & $-7.470(0.000)$ & $-6.138(0.000)$ & 0.366 & 0.690 \\
\hline Scientific research, technical services & $-1.443(0.075)$ & $-4.888(0.000)$ & 0.581 & -- \\
\hline $\begin{array}{l}\text { Public management, } \\
\text { social organizations }\end{array}$ & $-0.058(0.477)$ & $-5.407(0.000)$ & 0.685 & -- \\
\hline
\end{tabular}

Note: The sample period is from 1995 to 2005 and the data set is based on 29 provinces. However, as for the RPI, the sample period is from 1985 to 2005 based on 27 provinces (excluding Hubai and Hunan). Wages are categorized according to the sector; Agriculture, forestry, animal husbandry, fishing sector (Sector 1), Mining sector (Sector 2) and so on. The standard errors are calculated using the bootstrap method (10,000 replications), and figures in parentheses are $p$-values. The convergence speed (half-life) is calculated only for sectors where both tests reject the null.

many other provinces in its market accessibility since after all it is the country's capital. A recent study (Amiti and Cameron 2007) shows that the firms in Indonesia with good market access can afford more than 20 percent higher wages, and such wage increases spread only within a limited area outside the firms. While state-owned firms are still a significant presence in China, this could perhaps be a partial explanation for wage increases in many other provinces not matching those in Beijing. Our result from the sector-level analysis seems to suggest that these two factors are significant in the five sectors.

Finally, we have computed the convergence speed for relative prices and wages, the half-life of a shock to $q_{i, t}$ based on the MP test (Table 1). ${ }^{7}$ Using the formula, 
$\ln (0.5) / \ln (\rho)$ which has been often used in this type of research, we have computed $\rho$ which is common to all provinces under the null and thus it enables us to draw a general conclusion on convergence speed. This table shows that a shock to relative prices decreases by 50 percent in less than one year. Furthermore, the adjustment speed for the RPI is faster than the CPI. This is consistent with the view that aggregated data tends to exhibit a slower adjustment speed than disaggregated (micro) data (Imbs, Mumtaz, Ravn and Rey 2005). In addition, our estimated speed is clearly faster than that reported from the international PPP, which is consistent with the fact that this study deals with more homogeneous areas. Interestingly, the convergence speed of prices is faster than that of wages, showing evidence of a slow wage adjustment in China.

In the next section, the relative price-wage relationship is analyzed on the sectoral level. However, the results for these five sectors need to be interpreted carefully for the reason explained above.

\section{Explanations of Price Differentials}

While we find that local prices move in tandem with Beijing's in the long-run, this does not mean that prices are always identical to those in Beijing. It is well recognized the importance of analyzing the persistence of prices when conducting monetary policy which results from the backward looking behavior of consumers (Benigno and Löpez-Salido 2002). Thus, the next question is what factors can explain the deviation from PPP. Here, we shall consider wage differentials suggested by the BS theorem as a candidate in explaining relative prices. This relationship can be estimated by the following equation. ${ }^{8}$

$$
q_{i, t}=\beta_{0}+\beta_{1} y_{i, t}^{j}+u_{i, t}
$$

where $q_{i, t}$ is a panel of log relative prices and $y_{i, t}$ is $\log$ relative wages. Our benchmark city, Beijing, has relatively high wages. ${ }^{9}$ The subscript, $j$, represents economic sectors $(j=1,2,3, \ldots, 15)$ (see Table 1 for an explanation of these sectors). The term, $u_{i, t}$, is a residual. Parameter $\beta_{1}$ can be interpreted as the elasticity of relative

\footnotetext{
${ }^{7}$ See MP (2004) for details of how to derive the common $\rho$.

${ }^{8}$ Krugman (1991) also derived the same relationship between relative prices and wages when deriving his trade model.
} 
wages to relative prices. According to equation (7), a positive relationship exists between the relative prices and wages, and notably the increase in home wages, regardless of sectors, results in appreciation of the real exchange rate (or relative prices). However, unlike the standard specification of the Balassa-Samueslon effect, the numerator can be viewed here as a province with high productivity although $\beta_{l}$ is still expected to be positive suggesting higher prices in Beijing are explained by high wages over there.

Fortunately, this analysis can be carried out since the average wage data are available for 15 industries from 1995 to $2005 .{ }^{10}$ The empirical results are reported in Table 2 where we obtain $p$-values based on the bootstrap method. The results

Table 2. Relative Prices and Wages (Based on CPI) I

\begin{tabular}{lccc}
\hline & All & East & Middle/West \\
Relative wages in the sector & $\beta_{1}$ & $\beta_{1}$ & $\beta_{1}$ \\
\hline Agriculture, forestry, animal husbandry, fishing & $0.014(0.000)$ & $0.018(0.000)$ & $0.012(0.000)$ \\
Mining & $0.016(0.000)$ & $0.021(0.001)$ & $0.013(0.000)$ \\
Manufacturing & $0.015(0.000)$ & $0.023(0.000)$ & $0.013(0.000)$ \\
Production/distribution of electricity, gas, water & $0.007(0.004)$ & $0.013(0.027)$ & $0.006(0.049)$ \\
Construction & $0.015(0.000)$ & $0.024(0.000)$ & $0.012(0.001)$ \\
Management of water, conservancy & $0.008(0.000)$ & $0.014(0.001)$ & $0.007(0.018)$ \\
Transport, storage, postage & $0.017(0.000)$ & $0.028(0.000)$ & $0.014(0.000)$ \\
Wholesale, retail trade & $0.009(0.002)$ & $0.016(0.000)$ & $0.007(0.000)$ \\
Financial intermediation & $0.004(0.003)$ & $0.008(0.005)$ & $0.003(0.065)$ \\
Real estate & $0.011(0.000)$ & $0.022(0.000)$ & $0.009(0.000)$ \\
Services to households, other services & $0.016(0.000)$ & $0.033(0.000)$ & $0.012(0.000)$ \\
Health, social security and welfare & $0.008(0.000)$ & $0.014(0.001)$ & $0.007(0.001)$ \\
Education & $0.011(0.000)$ & $0.017(0.000)$ & $0.009(0.000)$ \\
Scientific research, technical services & $0.008(0.001)$ & $0.014(0.007)$ & $0.006(0.009)$ \\
Public management, social organizations & $0.008(0.000)$ & $0.013(0.016)$ & $0.006(0.010)$ \\
\hline
\end{tabular}

Note: Based on equation (12). The sample period is from 1995 to 2005. The standard errors are calculated using the bootstrap method (10,000 replications), and figures in parenthesis are $p$-values. All regions consist of 29 provinces defined in the main text. The eastern region includes Beijing, Tianjin, Hebei, Liaoning, Shanghai, Jiangsu, Zhejiang, Fujian, Shandong, Guangdong, Guangxi and Hainan. The western region comprises Sichuan, Guizhou, Yunnan, Shaanxi, Gansu, Qinghai, Ningxia and Xinjiang. The remaining provinces, Shanxi, Inner Mongolia, Jilin, Heilongjiang, Anhui, Jiangxi, Henan, Hubei and Hunan, are in the middle region.

\footnotetext{
${ }^{9} \mathrm{We}$ acknowledge that the results reported in this paper are somewhat sensitive to the choice of the benchmark. Results similar to those reported here however can be obtained when the benchmark is chosen out of the rich provinces like Shanghai. Searching explanations for this outcome is beyond the scope of this paper, and we shall leave it for future study.
} 
here are on the basis of different sectors, and in addition we analyzed the data subsets, the western and eastern/middle areas. We do not make any distinction between the eastern and middle areas due to the limited observations. ${ }^{11}$

Generally speaking, Table 2 shows that the results using relative wages are consistent with economic theory. The parameters for the wage differential are significant and positive. It thus confirms that relatively high prices in Beijing result from its high wages. The result is consistent with the fact that living expenses (e.g., electricity, water, taxi) are much more expensive in Beijing and the system of financial subsidies often exists to make up for these extra expenses. Furthermore, the results remain unchanged regardless of sector type. Thus, while discussion of this effect often focuses on different performance in tradable goods sectors across provinces (or countries), this study indicates consideration of both sectors will yield a more fruitful and realistic result when analyzing movements in the real exchange rate in China. This thus supports the finding of MacDonald and Ricci (2005) and Altissimo, Benigno and Palenzuela (2005) who argue that the nontradable sector has a significant impact on the real exchange rate. Our finding is also consistent with Guillaumont Jenneney and Hua using productivity data and similar studies of other countries/regions (Chen 2004, Nagayasu and Inakura 2006), and suggests that significant regional differences are a quite common phenomenon internationally. Finally, while one may expect to have a stronger price-wage relationship in the western/middle (poor) areas since Beijing, our benchmark, is a high growth province, our results do not markedly differ among these areas. It follows then that there may be a significant discrepancy in economic development even within eastern provinces.

Finally, we also checked whether our results are sensitive to the competitiveness level of each province since our theoretical model often hinges on such an assumption (Table 3). The National Bureau of Statistics of China disseminates the competitiveness index by province. This index is available from their web site (http://stats.gov.cn) only for the manufacturing sector in 2005. Therefore, we reexamine the relative price--wage relationship by classifying provinces to high and low competition provinces and assuming that provinces with high competition in the manufacturing sector also possess high competition in other sectors. The results

\footnotetext{
${ }^{10}$ Due to a change in industry classification used in data from 2003 , we have created one data set by combining two separate data sets.

${ }^{11}$ See Table 2 for a definition of the west, east and middle regions.
} 
Table 3. Relative Prices and Wages (Based on CPI) II

\begin{tabular}{lcc}
\hline \multicolumn{1}{c}{ Relative wages in the sector } & High competition & Low competition \\
\hline Agriculture, forestry, animal husbandry, fishing & $0.013(0.000)$ & $\beta_{1}$ \\
Mining & $0.014(0.001)$ & $0.014(0.000)$ \\
Manufacturing & $0.015(0.000)$ & $0.015(0.000)$ \\
Production/distribution of electricity, gas, water & $0.006(0.128)$ & $0.008(0.014)$ \\
Construction & $0.013(0.002)$ & $0.016(0.000)$ \\
Management of water, conservancy & $0.008(0.007)$ & $0.008(0.021)$ \\
Transport, storage, postage & $0.016(0.000)$ & $0.018(0.000)$ \\
Wholesale, retail trade & $0.009(0.000)$ & $0.009(0.000)$ \\
Financial intermediation & $0.004(0.052)$ & $0.004(0.015)$ \\
Real estate & $0.012(0.000)$ & $0.011(0.000)$ \\
Services to households, other services & $0.018(0.000)$ & $0.015(0.000)$ \\
Health, social security and welfare & $0.008(0.004)$ & $0.009(0.002)$ \\
Education & $0.010(0.001)$ & $0.011(0.000)$ \\
Scientific research, technical services & $0.007(0.047)$ & $0.009(0.004)$ \\
Public management, social organizations & $0.007(0.061)$ & $0.008(0.007)$ \\
\hline
\end{tabular}

Note: Based on equation (12). The sample period is from 1995 to 2005. The standard errors are calculated using the bootstrap method (10,000 replications), and figures in parenthesis are $p$-values. All regions consist of 29 provinces defined in the main text. The provinces are classified into two groups: high competitive provinces with the competitiveness indices of more than 79 points and low competitive provinces with less than 79 points. According to this classification, the high competitive provinces are Jiangsu, Fujian, Shanghai, Guangdong, Beijing, Tianjin, Zhejiang, Liaoning, Shandong, Sichuan, Jilin, Guizhou, Hunan, Anhui, Shaanxi, and Hubei. The low competitive provinces are the rest of the provinces.

are reported in Table 3 and suggest that basically the same results are obtained from the two groups of data sets, confirming the importance of wages in determining prices in China.

\section{Summary and Discussion}

Using Chinese provincial data, we examined the relative price--wage relationship using the Balassa-Samuelson (BS) framework. This study was recently analyzed often in the context of industrialized countries, particularly for the euro areas where there is only one monetary policy and there is a need to understand whether the euro member countries are homogenous. Like the euro zone, China has a central bank with heterogeneous economies and culture, which motivated this research.

Here, the real exchange rate is measured by the prices of a local province vis-a- 
vis those in the benchmark (Beijing), and the wage ratio is used as the factor explaining the price ratio. First, considering cross sectional dependency in our data, we implement recently developed panel unit root tests. We find evidence of non-divergence in Chinese provincial prices (i.e., PPP) and therefore support monetary union in China. But less strong evidence of non-divergence is obtained for relative wages. Notably, the overall wage ratio did show evidence of divergence (i.e., the unit root), thereby suggesting overall wages in some provinces are not following Beijing's wage level and confirming increased income disparity among provinces in China. However, some sector-level wages are found to be non-divergent, and using such data, we report that relative wages explain the deviation in price differentials in most sectors despite the significant presence of state-own enterprises in China.

\section{Acknowledgments}

This research was initiated when Liu was a graduate student at University of Tsukuba. We would like to thank for useful comments Jong-Eun Lee (managing editor), anonymous referees, Mardi Dungey, Eiji Fujii, Carsten A. Holz, Takatoshi Ito, Tadashi Kikuchi, Louis Kuijs, Kai Li, Naonobu Minato, Masakatsu Okubo, Shinji Takagi, Derya Filiz Unsal, Takashi Unayama, Zhenquan Wang, and conference participants at the All China Economic International Conference (Hong Kong, 2006), the Foundation for Advanced Studies on International Development (FASID) (Tokyo, 2007), the Japan Economic Association Conference (Osaka, 2007), and the 5th INFINITI Conference on International Finance (Dublin, 2007). This study was partially supported by a grant from the FASID. All remaining errors are ours.

Received 31 July 2007, Accepted 17 October 2007

\section{References}

Altissimo, F., Benigno, P. and Palenzuela, D. R. (2005) Long-run determinants of inflation differentials in a monetary union. NBER Working Paper Series 11473.

Amiti, M. and Cameron, L. (2007) Economic geography and wages. Review of Economic and Statistics 89(1), 15-29.

Bai, J. and Ng, X. (2002) Determining the number of factors in approximate factor models. Econometrica 70, 191-221.

Bai, J. and Ng, X. (2004) A PANIC attack on unit roots and cointegration. Econometrica 
72(4), 1127-1177.

Banerjee, A., Marcellino, M. and Osbat, C. (2005) Testing for PPP: should we use panel methods? Empirical Economics 30, 77-91.

Benigno, P., and Löpez-Salido, J. D. (2002) Inflation persistence and optimal monetary policy in the euro area. European Central Bank Working Paper Series No. 178.

Canzoneri, M.B., Cumby, R.E. and Diba, B. (1999) Relative labor productivity and the real exchange rate in the long-run: evidence for a panel of OECD countries. Journal of International Economics 47, 245-266.

Cecchetti, S. G., Mark, N. C. and Sonora, R. J. (2002) Price index convergence among United States cities. International Economic Review 43, 1081-1099.

Chen, N. (2004) The behavior of relative prices in European Union: a sectoral analysis. European Economic Review 48, 1257-1286.

Engle, C. and Rogers, J. H. (1996) How wide is the border? American Economic Review $85,1112-1125$.

Esaka, T. (2003) Panel unit root tests of purchasing power parity between Japanese cities, 1960-1988: disaggregated price data. Japan and the World Economy 15, 233-244.

Fisher, R. A. (1932) Statistical methods for research workers, 4th ed.. Oliver and Boyd, Edinburgh.

Goldberg, P. K., and Verboven, F. (2005) Market integration and convergence to the law of one price: evidence from the European car market. Journal of International Economics $65,49-73$.

Honohan, P., and Lane, P. (2003) Inflation divergence, Economic Policy (October) 357-394.

Inagaki, H. (2006) South China's labor shortage-will the current worker shortage escalate? Mizuho Research Paper 9, Mizuho Research Institute.

Im, K. S., Pesaran, M. H. and Shin, Y. (2003) Testing for unit roots in heterogenous panels. Journal of Econometrics 115, 53-75.

Imbs, J., Mumtaz, H., Ravn, M. O. and Rey, H. (2005) PPP strikes back: aggregation and the real exchange rate. Quarterly Journal of Economics CXX(1) 1-43.

Levin, A., Lin, C-F. and Chu, C. (2002) Unit root test in panel data: asymptotic and finite sample properties. Journal of Econometrics 108, 1-24.

MacDonald, R., and Ricci, L.A. (2005) The real exchange rate and the Balassa-Samuelson effect: the role of the distribution sector, Pacific Economic Review 10(1), 29-48.

MacDonald, R., (2006) Panel unit root tests and real exchange rates, Economics Letters 50, 7-11

Maddala, G. S., Wu, S. (1999) A comparative study of unit root tests with panel data and a new simple test. Oxford Bulletin of Economics and Statistics, 631-652.

Moon, H. R. and Perron, B. (2004) Testing for a unit root in panels with dynamic factors. Journal of Econometrics 112, 81-126.

Nagayasu, J., and Inakura, N. (2006) Purchasing power parity: further evidence from Japanese municipal data. Presented at the Annual Meeting of the Japanese Economic Association, June.

Parsley, D. C. and Wei, S-J. (1996) Convergence to the law of one price without trade 
barriers or currency fluctuations. Quarterly Journal of Economics 111, 1211-1236.

Rogers, J. H. (2001) Price level convergence, relative prices, and inflation in Europe. FRB International Finance Discussion Paper No.699.

Rogoff, K. (1996) The purchasing power parity puzzle. Journal of Economic Literature $34,647-668$. 